\title{
Part-load performance of a high temperature Kalina cycle
}

\author{
Modi, Anish; Andreasen, Jesper Graa; Kærn, Martin Ryhl; Haglind, Fredrik
}

Published in:

Energy Conversion and Management

Link to article, DOI:

10.1016/j.enconman.2015.08.006

Publication date:

2015

Document Version

Peer reviewed version

Link back to DTU Orbit

Citation (APA):

Modi, A., Andreasen, J. G., Kærn, M. R., \& Haglind, F. (2015). Part-load performance of a high temperature Kalina cycle. Energy Conversion and Management, 105, 453-461.

https://doi.org/10.1016/j.enconman.2015.08.006

\section{General rights}

Copyright and moral rights for the publications made accessible in the public portal are retained by the authors and/or other copyright owners and it is a condition of accessing publications that users recognise and abide by the legal requirements associated with these rights.

- Users may download and print one copy of any publication from the public portal for the purpose of private study or research.

- You may not further distribute the material or use it for any profit-making activity or commercial gain

- You may freely distribute the URL identifying the publication in the public portal 


\title{
Part-load performance of a high temperature Kalina cycle
}

\author{
Anish Modi*, Jesper Graa Andreasen, Martin Ryhl Kærn, Fredrik Haglind \\ Department of Mechanical Engineering, Technical University of Denmark, Nils Koppels Allé, Building 403, \\ DK-2800 Kgs. Lyngby, Denmark
}

\begin{abstract}
The Kalina cycle has recently seen increased interest as an alternative to the conventional steam Rankine cycle. The cycle has been studied for use with both low and high temperature applications such as geothermal power plants, ocean thermal energy conversion, waste heat recovery, gas turbine bottoming cycle and solar power plants. The high temperature cycle layouts are inherently more complex than the low temperature layouts due to the presence of a distillation-condensation subsystem, three pressure levels and several heat exchangers. This paper presents a detailed approach to solve the Kalina cycle in part-load operating conditions for high temperature (a turbine inlet temperature of $500{ }^{\circ} \mathrm{C}$ ) and high pressure (100 bar) applications. A central receiver concentrating solar power plant with direct vapour generation is considered as a case study where the part-load conditions are simulated by changing the solar heat input to the receiver. Compared with the steam Rankine cycle, the Kalina cycle has an additional degree of freedom in terms of the ammonia mass fraction which can be varied in order to maximize the part-load efficiency of the cycle. The results include the part-load curves for various turbine inlet ammonia mass fractions, and the fitted equations for these curves.
\end{abstract}

Keywords: Kalina cycle, part-load, ammonia-water mixture, concentrating solar power plant

\section{Introduction}

The Kalina cycle was introduced in 1984 [1] as an alternative to the conventional Rankine cycle to be used as a bottoming cycle for combined cycle power plants. It uses a mixture of ammonia and water as the working fluid, instead of pure water as in the case of a steam

5 Rankine cycle. The composition of the ammonia-water mixture could be varied by changing the ammonia mass fraction in the mixture, i.e. the ratio of the mass of ammonia in the ammonia-water mixture to the total mass of the mixture. This change in the composition affects the thermodynamic and the transport properties of the mixture [2]. Since its

\footnotetext{
${ }^{*}$ Corresponding author. Tel.: +4545251910

Email address: anmod@mek.dtu.dk (Anish Modi)
} 


\section{Nomenclature}

Abbreviations

CSP concentrating solar power

GA genetic algorithm

PPTD pinch point temperature difference, ${ }^{\circ} \mathrm{C}$

\section{Symbols}

$\Delta h \quad$ specific enthalpy difference, $\mathrm{J} \mathrm{kg}^{-1}$

$\Delta T$ temperature difference, ${ }^{\circ} \mathrm{C}$

$\delta \quad$ tolerance

$\dot{m} \quad$ mass flow rate, $\mathrm{kg} \mathrm{s}^{-1}$

$\dot{Q} \quad$ heat rate, MW

$\dot{q} \quad$ heat input relative to the design value

$\dot{W} \quad$ work or electrical power, MW

$\eta \quad$ efficiency

A area, $\mathrm{m}^{2}$

$c_{p}$ isobaric specific heat capacity, $\mathrm{J} \mathrm{kg}^{-1} \mathrm{~K}^{-1}$

$F_{c u} \quad$ copper loss fraction

$k_{\text {tur }} \quad$ turbine constant, $\mathrm{kg} \mathrm{K}^{0.5} \mathrm{~s}^{-1} \mathrm{bar}^{-1}$

$L \quad$ load relative to the design value

$N \quad$ rotational speed, rpm

$p \quad$ pressure, bar

$T \quad$ temperature, ${ }^{\circ} \mathrm{C}$ or $\mathrm{K}$

$U$ overall heat transfer coefficient, $\mathrm{W} \mathrm{m}^{-2} \mathrm{~K}^{-1}$

$X \quad$ vapour quality

$x \quad$ ammonia mass fraction

Subscripts, including components c cold fluid

cd condenser

$\mathrm{cw}$ condenser cooling water

cy cycle

d design condition

gen generator

i $\quad i^{\text {th }}$ control volume

is isentropic

lm logarithmic mean temperature difference, ${ }^{\circ} \mathrm{C}$

m mechanical

$\mathrm{mx} \quad$ mixer

net net electrical output from the power cycle

pl relative plant load in part-load condition

pp pinch point temperature difference, ${ }^{\circ} \mathrm{C}$

pp,cd minimum pinch point temperature difference in the condensers, ${ }^{\circ} \mathrm{C}$

pp,re minimum pinch point temperature difference in the recuperators, ${ }^{\circ} \mathrm{C}$

pu pump

re recuperator

rec receiver/boiler

sep separator

spl splitter

thv throttle valve

tur turbine 
introduction, several uses for the Kalina cycle have been proposed for low temperature applications or low grade heat utilization. Examples include their use in a geothermal power plants [3], for waste heat recovery [4-7], for exhaust heat recovery in a gas turbine modular helium reactor [8], in combined heat and power plants $[9,10]$, coupled with a coal-fired steam power plant for exhaust heat recovery [11], as a part of Brayton-Rankine-Kalina triple cycle [12], and in solar power plants [13,14]. For high temperature applications, the Kalina cycles have been investigated to be used as gas turbine bottoming cycles [15-18], for industrial waste heat recovery, biomass based cogeneration and gas engine waste heat recovery [19], for direct-fired cogeneration applications [20], and in concentrating solar power (CSP) plants $[21,22]$.

There have been discussions regarding the feasibility of using ammonia-water mixtures at high temperatures due to the nitridation effect resulting in the corrosion of the equipment. However, the use of an ammonia-water mixture as the working fluid at high temperature has been successfully demonstrated in Canoga Park with turbine inlet conditions of $515{ }^{\circ} \mathrm{C}$ and 110 bar [23]. Moreover, a patent by Kalina [24] claims the stability of ammonia-water mixtures along with prevention of nitridation for plant operation preferably up to $1093{ }^{\circ} \mathrm{C}$ for temperature and 689.5 bar for pressure using suitable additives. Water itself prevents the ammonia in the mixture from corroding the equipment up to about $400{ }^{\circ} \mathrm{C}$, and above this temperature, the amount of the additive is far below the threshold for it cause any damage [25].

None of the previous studies for the Kalina cycles have considered the performance of the Kalina cycle in part-load conditions. Moreover, the layout for the high temperature Kalina cycles is inherently more complex than those used for the low temperature applications. This is primarily because of the presence of a distillation-condensation subsystem, at least three pressure levels and several heat exchangers. In applications such as solar power plants where the heat input fluctuates throughout the day, and over the year, it is essential to include the part-load performance of the power cycle to assess the plant performance in a thorough manner. Similarly, it is also necessary to evaluate the part-load performance of the power cycle in other cases such as waste heat recovery from diesel engines or other fluctuating sources of energy input. The Kalina cycles have an additional degree of freedom in terms of the ammonia mass fraction, as compared with using pure working fluids, which makes it possible to obtain better part-load performance characteristics by changing the ammonia mass fraction to suit the part-load conditions. To the authors' knowledge, only Kalina and Leibowitz [26] and Smith et al. [27] presented performance curves for the part-load conditions using a Kalina cycle. Kalina and Leibowitz [26] mentioned that the second law efficiency of the Kalina bottoming cycle for a gas turbine changes by about 3.2 percentage points when the cycle load reduces by $25 \%$. The paper did not present any details about the assumptions or the methodology used for calculating the part-load performance of the Kalina cycle. Moreover, the part-load performance until only $75 \%$ plant load was presented.

Smith et al. [27] presented the part-load performance curves for a simple gas turbine cycle, a Rankine combined cycle, and a Kalina combined cycle. The Kalina combined cycle showed the best performance. The operational advantages of the Kalina cycle as compared with the Rankine cycle were also presented. This paper also did not provide the part-load 
characteristics of only the Kalina cycle, or any methodology for evaluating the part-load performance characteristics. From the Kalina combined cycle part-load curve, the part-load performance of only the Kalina cycle cannot be estimated without knowing the combined cycle operation and control strategy, which was also not presented in the paper. A recent patent by Mlcak and Mirolli [28] suggests varying the ammonia mass fraction in order to improve the system performance of the Kalina cycle with varying ambient conditions. The patent however discusses a relatively simpler low temperature application layout to be used with geothermal hot water or industrial waste heat sources.

The objective of this paper is to present the detailed methodology of solving a Kalina cycle at part-load conditions for high temperature applications. As a case, a central receiver CSP plant with direct vapour generation is considered. The part-load conditions were simulated by changing the solar heat input to the receiver, and the cycle was solved in part load by varying the separator inlet ammonia mass fraction and adjusting the pump outlet pressures. In the paper, Section 2 presents the design point optimization and the part-load modelling approaches along with the assumptions; Section 3 presents the results from the part-load modelling; Section 4 discusses the results; and Section 5 concludes the paper.

\section{Methods}

The Kalina cycle layout investigated in this paper, named KC12 [22], is shown in Fig. 1. The cycle components in the layout are shown in abbreviated forms where REC is the receiver/boiler, TUR is the turbine, GEN is the generator, SEP is the vapour-liquid separator, $\mathrm{RE} *$ is the recuperator, $\mathrm{PU} *$ is the pump, $\mathrm{CD} *$ is the condenser, $\mathrm{MX} *$ is the mixer (where ' $*$ ' denotes the respective component number), SPL is the splitter and THV is the throttling valve.

In the cycle, the superheated ammonia-water mixture (stream 1), i.e. the working solution, expands in the turbine and is subsequently mixed in the mixer MX1 with the ammonia lean liquid from the separator SEP to lower the ammonia mass fraction in the condenser CD1. The fluid after the mixer MX1 is called the basic solution. The ammonia rich vapour from the separator SEP is later mixed in the mixer MX2 with a part of the basic solution from the splitter SPL to again form the working solution. This working solution then goes through the condenser CD2 and the pump PU2. The external heat input to the working fluid is provided in the boiler. In the case considered in this study, the boiler is the solar receiver REC.

All the simulations were performed using MATLAB R2015a [29]. The thermodynamic properties for the ammonia-water mixtures were calculated using the REFPROP 9.1 interface for MATLAB [30]. The default property calculation method for the ammonia-water mixtures in REFPROP is using the Tillner-Roth and Friend formulation [31]. However, this formulation in REFPROP is highly unstable and fails to converge on several occasions, especially in the two-phase regions, near the critical point and at higher ammonia mass fractions. Therefore, an alternative formulation called 'Ammonia (Lemmon)' [32] was used. It was found to be more stable and with fewer convergence failures, without significantly compromising on the accuracy of the calculations [22]. 


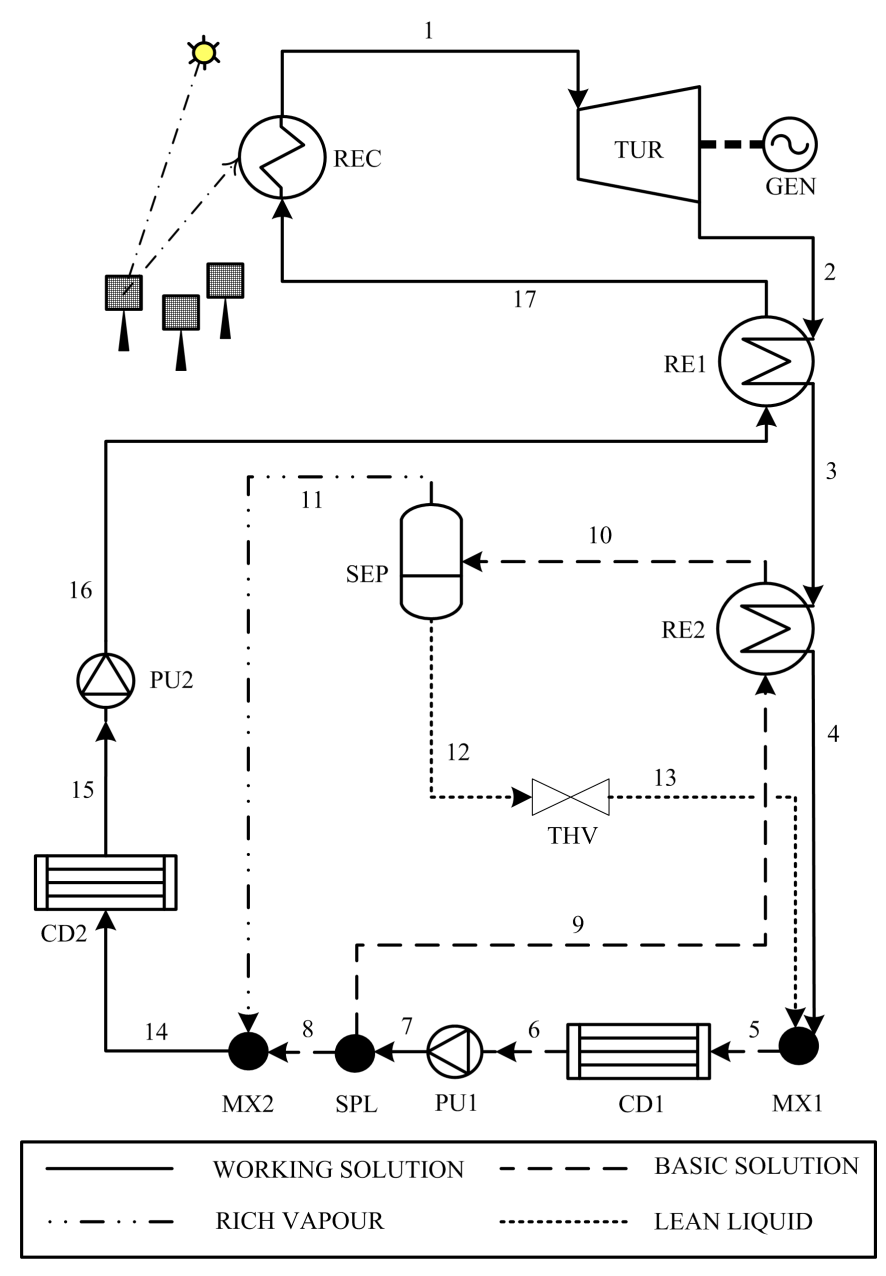

Figure 1: Kalina cycle KC12.

\subsection{Design optimization}

In order to model the Kalina cycle in part-load conditions, it was first necessary to obtain the cycle performance characteristics and the thermodynamic states at the design point of operation. A detailed methodology to solve and optimize the Kalina cycle at design point using a genetic algorithm (GA) was presented by Modi and Haglind [22]. For the KC12 layout (Fig. 1), the algorithm to optimize the cycle and obtain the design condition parameters is shown in Fig. 2. The cycle was thermodynamically optimized by maximizing the cycle efficiency for a given net electrical power output. The turbine outlet pressure, the separator inlet temperature and the separator inlet ammonia mass fraction were the decision variables for the optimization. The turbine inlet ammonia mass fraction was varied for parametric analysis in order to analyse the cycle behaviour for a range of values. The following assumptions were made for the cycle design optimization $[18,22]$ :

a. The cycle was modelled in steady state.

b. The turbine inlet temperature and pressure were fixed at $500{ }^{\circ} \mathrm{C}$ and 100 bar. The 
isentropic efficiencies of the turbine and the pumps were $85 \%$ and $70 \%$ respectively. The turbine mechanical efficiency and the generator efficiency were both $98 \%$.

c. The plant was designed for a net electrical power output of $20 \mathrm{MW}$. The minimum allowed vapour quality at the turbine outlet was $90 \%$. The condenser cooling water inlet and outlet temperatures were fixed at $20{ }^{\circ} \mathrm{C}$ and $30{ }^{\circ} \mathrm{C}$.

d. The recuperators and the condensers had a minimum pinch point temperature difference (PPTD) of $8{ }^{\circ} \mathrm{C}$ and $4{ }^{\circ} \mathrm{C}$ respectively.

e. Pressure drops and heat losses were neglected.

f. The minimum separator inlet vapour quality was fixed at $5 \%$.

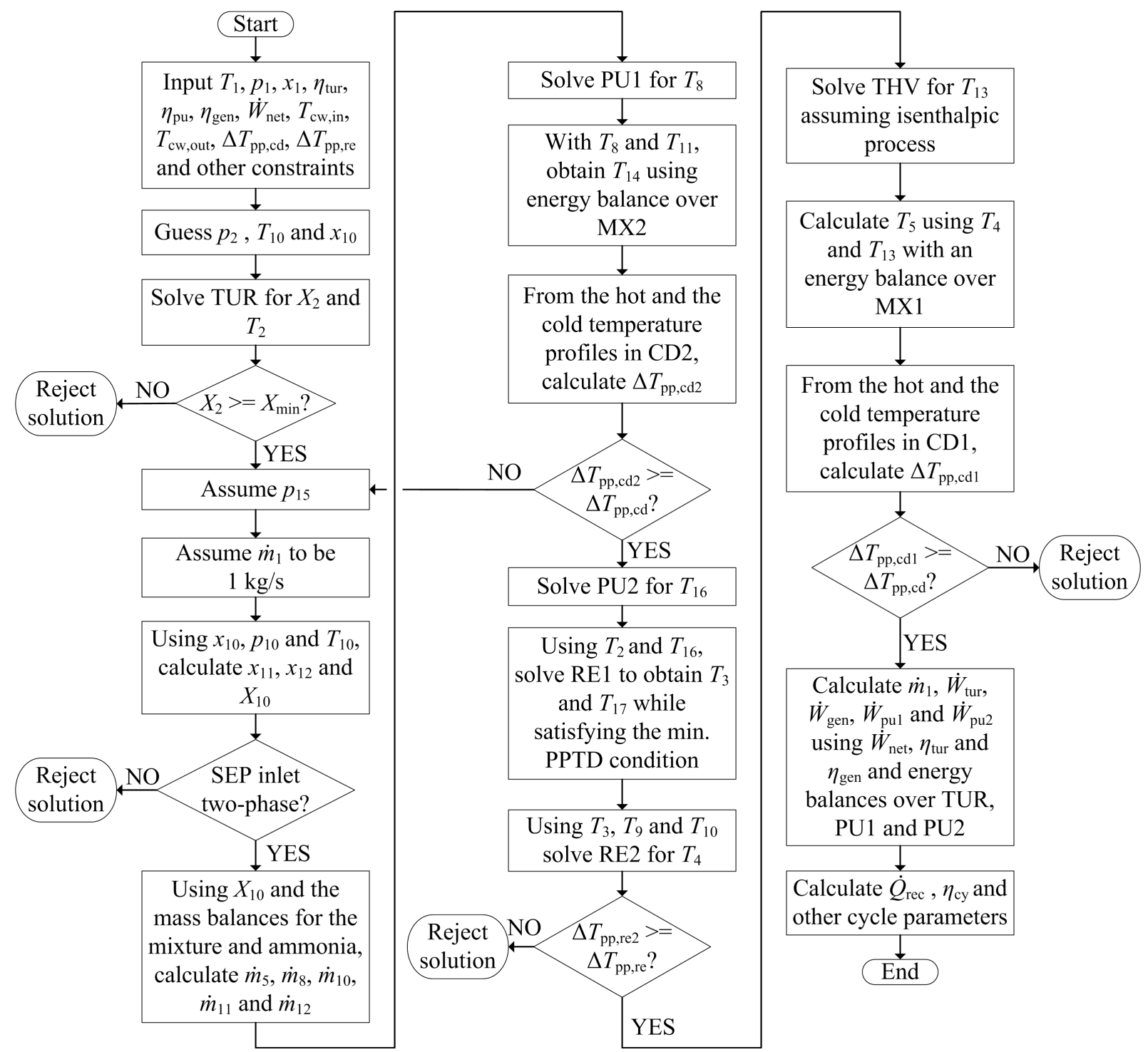

Figure 2: Solution algorithm for every iteration of the Kalina cycle KC12 for design calculation using GA. 
In general, the following steps were used to solve the Kalina cycle for each iteration of the optimization process. The turbine TUR was solved first to obtain the state at the turbine outlet. Assuming a condenser pressure for the condenser CD2, the mass flow rates were then obtained using a simplified configuration as presented by Marston [15]. With respect to the mass flow rates at different points in the cycle, the entire cycle can be represented by the simplified layout as shown in Fig. 3.

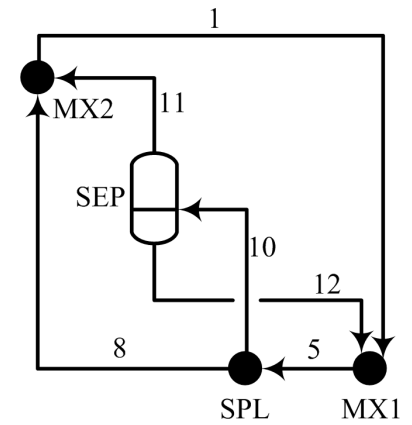

Figure 3: Simplified configuration of the Kalina cycle KC12 with respect to different mass flow rates in the cycle.

The mass balance equations for the ammonia-water mixture and ammonia in the mixture, and the ammonia mass fraction balance equations are:

$$
\begin{aligned}
\dot{m}_{5} & =\dot{m}_{1}+\dot{m}_{12} \\
\dot{m}_{5} \cdot x_{5} & =\dot{m}_{1} \cdot x_{1}+\dot{m}_{12} \cdot x_{12} \\
\dot{m}_{1} & =\dot{m}_{8}+\dot{m}_{11} \\
\dot{m}_{1} \cdot x_{1} & =\dot{m}_{8} \cdot x_{8}+\dot{m}_{11} \cdot x_{11} \\
\dot{m}_{10} & =\dot{m}_{11}+\dot{m}_{12} \\
\dot{m}_{10} \cdot x_{10} & =\dot{m}_{11} \cdot x_{11}+\dot{m}_{12} \cdot x_{12} \\
\dot{m}_{11} & =\dot{m}_{10} \cdot X_{10} \\
x_{5} & =x_{10} \\
x_{8} & =x_{10}
\end{aligned}
$$

where $\dot{m}$ is the mass flow rate, $x$ is the ammonia mass fraction and $X$ is the vapour quality.

The mass balances are over the mixer MX1 (Eqs. 1 and 2), the mixer MX2 (Eqs. 3 and 4) and the separator SEP (Eqs. 5 and 6). The ammonia mass fraction balances are over the splitter SPL (Eqs. 8 and 9). Since the separator SEP is simply a vapour-liquid separator, Eq. 7 only relates the mass flow rate of stream 11 to the mass flow rate and the vapour quality of the stream 10 . On rearranging the above equations, the following relations are 
obtained:

$$
\begin{aligned}
\frac{\dot{m}_{10}}{\dot{m}_{1}} & =\frac{x_{1}-x_{10}}{X_{10} \cdot\left(x_{11}-x_{10}\right)} \\
\frac{\dot{m}_{8}}{\dot{m}_{1}} & =\frac{x_{11}-x_{1}}{x_{11}-x_{10}}
\end{aligned}
$$

These relations were then used to calculate the different mass flow rates after assuming $\dot{m}_{1}$ to be $1 \mathrm{~kg} \mathrm{~s}^{-1}$ as an initial guess value, and calculating the values of the ammonia mass fractions for the two outlet streams of the separator $\left(x_{11}\right.$ and $\left.x_{12}\right)$ with REFPROP using the state at the separator inlet as input. This was done repeatedly until the PPTD in the condenser CD2 became greater than or equal to the minimum PPTD value for the condensers.

Once the mass flow rates at different points in the cycle were known, and it was made sure that the inlet stream to the separator SEP is in two-phase flow, then the pumps, the mixers, the recuperators and the condensers were solved while satisfying all the design constraints such as minimum PPTD, minimum vapour quality at the turbine outlet, etc. and using the following equations:

TUR: $\dot{W}_{\text {tur }}=\dot{m}_{1} \cdot\left(h_{1}-h_{2}\right)$

GEN: $\dot{W}_{\text {gen }}=\dot{W}_{\text {tur }} \cdot \eta_{\text {tur }, \mathrm{m}} \cdot \eta_{\text {gen }}$

RE1: $\dot{m}_{2} \cdot\left(h_{2}-h_{3}\right)=\dot{m}_{16} \cdot\left(h_{17}-h_{16}\right)$

RE2: $\dot{m}_{3} \cdot\left(h_{3}-h_{4}\right)=\dot{m}_{9} \cdot\left(h_{10}-h_{9}\right)$

CD1: $\dot{m}_{5} \cdot\left(h_{5}-h_{6}\right)=\dot{m}_{\mathrm{cw}, \mathrm{cd} 1} \cdot c_{p, \mathrm{cw}} \cdot\left(T_{\mathrm{cw}, \mathrm{out}}-T_{\mathrm{cw}, \mathrm{in}}\right)$

CD2: $\dot{m}_{14} \cdot\left(h_{14}-h_{15}\right)=\dot{m}_{\mathrm{cw}, \mathrm{cd} 2} \cdot c_{p, \mathrm{cw}} \cdot\left(T_{\mathrm{cw}, \mathrm{out}}-T_{\mathrm{cw}, \mathrm{in}}\right)$

PU1: $\dot{W}_{\text {pu1 }}=\dot{m}_{6} \cdot\left(h_{7}-h_{6}\right)$

PU2: $\dot{W}_{\mathrm{pu} 2}=\dot{m}_{15} \cdot\left(h_{16}-h_{15}\right)$

SEP: $\dot{m}_{10} \cdot h_{10}=\dot{m}_{11} \cdot h_{11}+\dot{m}_{12} \cdot h_{12}$

MX1: $\dot{m}_{5} \cdot h_{5}=\dot{m}_{4} \cdot h_{4}+\dot{m}_{13} \cdot h_{13}$

MX2: $\dot{m}_{14} \cdot h_{14}=\dot{m}_{8} \cdot h_{8}+\dot{m}_{11} \cdot h_{11}$

SPL: $h_{9}=h_{7}$

THV: $h_{12}=h_{13}$

where $\dot{W}_{\text {tur }}, \quad \dot{W}_{\text {pu }}$ and $\dot{W}_{\text {gen }}$ are respectively the turbine work output, the required pump work and the generator electrical power output, $\dot{m}$ is the mass flow rate, $h$ is the specific enthalpy, $c_{p}$ is the isobaric specific heat capacity, and $T$ is the temperature. The subscript 'cw' denotes the condenser cooling water.

The cycle efficiencies from the different combinations of the decision variables were compared, and the solution with the highest cycle efficiency was stored as the optimal solution for the given input of the turbine inlet ammonia mass fraction. The same procedure was then repeated for different values of the turbine inlet ammonia mass fractions. All the heat exchangers, including the condensers, were discretized into 50 control volumes and solved so that the position of the PPTD could be calculated with sufficient accuracy. The $U A$ values, 
i.e. the ratio of the heat transferred in any control volume to the logarithmic mean temperature difference over the control volume, for the different heat exchangers were obtained from:

$$
(U A)_{\mathrm{i}, \mathrm{d}}=\frac{\dot{Q}_{\mathrm{i}, \mathrm{d}}}{\Delta T_{\mathrm{lm}, \mathrm{i}, \mathrm{d}}}
$$

where $U, A, \dot{Q}$ and $\Delta T_{\mathrm{lm}}$ are respectively the overall heat transfer coefficient, heat transfer area, the heat transfer rate and the logarithmic mean temperature difference for the $i^{\text {th }}$ control volume at design point of operation.

\subsection{Validation}

In order to ensure the mathematical accuracy of the solution algorithm for the Kalina cycle, several check parameters related to the mixture mass balances, ammonia mass balances and energy balances over the different cycle components were included in the process. It was ensured that all the balances were satisfied with a residual below or equal to $0.001 \%$. The same was considered for the part-load model. In case there was an error in the calculation of the thermodynamic properties by REFPROP, or the balances were not satisfied within the specified tolerance, the solution was rejected.

To the authors' knowledge, there is no publication mentioning the operating states of a high temperature Kalina cycle that were either obtained experimentally, or from the measurements taken from a commercial plant. It was therefore only possible to validate the Kalina cycle models with the results from previously published modelling results. Only Marston [15] provides all the modelling assumptions and results in order to make a proper validation. The layout investigated by Marston [15] is what was referred to as KC234 in Modi and Haglind [22]. In order to validate the overall solution methodology, this layout was used. For different combinations of the turbine inlet ammonia mass fraction and the separator inlet temperature taken from Marston [15], it was found that the maximum deviation of the cycle efficiency values calculated from the current algorithm from those presented in Marston [15] was $2.21 \%$, with the average deviation being $1.01 \%$. This is using the same modelling assumptions as mentioned in Marston [15], but with the Kalina cycle solution methodology as used in Modi and Haglind [22], and in the current study. With these low deviations, the current solution algorithm was considered validated. The reason for selecting the KC12 layout to investigate the part-load performance of the Kalina cycle was because this layout was overall found to be more efficient than $\mathrm{KC} 234$ [22], while being simpler with fewer number of recuperators.

\subsection{Part-load modelling}

Once the thermodynamic states, the mass flow rates and the $U A$ values were obtained from the cycle design optimization, the part-load calculations were performed. The heat input to the receiver REC was gradually decreased and the part-load relative efficiency curves for different plant loads and turbine inlet ammonia mass fractions were prepared.

A solution algorithm similar to the validated design optimization algorithm was used for the part-load performance calculations, but with different decision variables and additional 
assumptions required for the part-load calculations. The following assumptions were made for the Kalina cycle steady-state part-load calculations. The turbine inlet temperature was maintained at the design value of $500{ }^{\circ} \mathrm{C}$ to have the highest temperature at the turbine inlet for better efficiency. The turbine inlet ammonia mass fraction was maintained at its respective design point value in order to avoid fluctuations in the turbine output as suggested in Amano et al. [33]. The condenser cooling water inlet temperature was assumed to be the same as its design value, as has been done in Lippke [34]. In order to satisfy the condensing load, the condenser cooling water mass flow rate would then adjusted by regulating the cooling water pump. The minimum separator inlet vapour quality was fixed at $2 \%$, a value smaller than the design value, but enough to ensure that there will be a two-phase flow at the separator inlet. The separator inlet ammonia mass fraction was allowed to vary within $\pm 1 \%$ of the design value to enable using the power law for heat exchanger off-design calculations. The condensers' working fluid outlet temperature was at least $2{ }^{\circ} \mathrm{C}$ higher than the cooling water inlet temperature. The tolerance $\delta$ in Fig. 4 was set to $0.1 \mathrm{~K}$. A more elaborate discussion regarding the part-load modelling assumptions is provided in Section 4.

The turbine was modelled in part load using the Stodola's ellipse law (Eq. 27) to calculate the turbine constant [35], and the off-design isentropic efficiency (Eq. 28) as described in Ray [36]:

$$
\begin{gathered}
k_{t u r}=\frac{\dot{m}_{1} \cdot \sqrt{T_{1}}}{\sqrt{p_{1}^{2}-p_{2}^{2}}} \\
\eta_{\text {tur }, \text { is }}=\eta_{\text {tur }, \text { sis }, \mathrm{d}}-2 \cdot\left[\frac{N}{N_{\mathrm{d}}} \cdot \sqrt{\frac{\Delta h_{\mathrm{is}, \mathrm{d}}}{\Delta h_{\mathrm{is}}}}-1\right]^{2}
\end{gathered}
$$

where $k_{\text {tur }}$ is the turbine constant, $\eta_{\text {tur,is }}$ and $\eta_{\text {tur, is,d }}$ are the turbine isentropic efficiencies at part-load and design conditions, $N$ and $N_{\mathrm{d}}$ are the turbine rotational speeds at part-load and design conditions, and $\Delta h_{\text {is }}$ and $\Delta h_{\text {is,d }}$ are the isentropic specific enthalpy differences at part-load and design conditions. The turbine speed in a power plant remains constant in order to maintain the generated electricity frequency, and therefore the ratio of the speeds in Eq. 28 is taken as unity [36]. The mechanical efficiency of the turbine was assumed the same as its design value.

The off-design isentropic efficiency of the pumps was obtained using [34]:

$$
\eta_{\mathrm{pu}, \mathrm{is}}=\eta_{\mathrm{pu}, \mathrm{is}, \mathrm{d}} \cdot\left[2 \cdot \frac{\dot{m}}{\dot{m}_{\mathrm{d}}}-\left(\frac{\dot{m}}{\dot{m}_{\mathrm{d}}}\right)^{2}\right]
$$

where $\eta_{\mathrm{pu} \text {,is }}$ and $\eta_{\mathrm{pu}, \mathrm{is}, \mathrm{d}}$ are pump efficiencies at part-load and design conditions, and $\dot{m}$ and $\dot{m}_{\mathrm{d}}$ are the mass flow rates through the pump at part-load and design conditions.

The off-design generator efficiency was obtained using [37]:

$$
\eta_{\text {gen }}=\frac{\eta_{\text {gen,d }} \cdot L_{\text {gen }}}{\eta_{\text {gen }, \mathrm{d}} \cdot L_{\text {gen }}+\left(1-\eta_{\text {gen }, \mathrm{d}}\right) \cdot\left[\left(1-F_{c u}\right)+F_{c u} \cdot L_{\text {gen }}^{2}\right]}
$$


where $F_{c u}$ is the copper loss fraction (assumed 0.43 [37]), $\eta_{\text {gen }}$ and $\eta_{\text {gen,d }}$ are the generator efficiencies at part-load and design conditions, and $L_{\text {gen }}$ is the generator load relative to the design value.

The heat exchangers were discretized once again in the part-load conditions to calculate the temperature profiles. As a first approximation, the $U A$ values in part load for each control volume was obtained using the power law with the cold side mass flow rate [38]:

$$
(U A)_{\mathrm{i}}=(U A)_{\mathrm{i}, \mathrm{d}} \cdot\left(\frac{\dot{m}_{\mathrm{c}}}{\dot{m}_{\mathrm{c}, \mathrm{d}}}\right)^{0.8}
$$

where $(U A)_{\mathrm{i}}$ and $(U A)_{\mathrm{i}, \mathrm{d}}$ are the $U A$ values at part-load and design conditions for the $i^{\text {th }}$ control volume in $\mathrm{W} \mathrm{K}^{-1}$, and $\dot{m}_{\mathrm{c}}$ and $\dot{m}_{\mathrm{c}, \mathrm{d}}$ are the mass flow rates of the cold fluid at part-load and design conditions.

For the part-load operation, the following control strategy was used. The turbine inlet pressure was varied in a sliding pressure operation to maintain the turbine inlet temperature at the design value. In order to obtain the highest part-load performance from the cycle, the separator inlet ammonia mass fraction was varied. In practice, it is easier to measure the temperatures and pressures in the cycle than the ammonia mass fraction, especially when the mixture is in two-phase flow. Since the pressure at the pump PU1 outlet is governed by the condenser CD2, the splitter SPL split fraction (i.e. the ratio of the mass flow rate of stream 9 to that of stream 7 in Fig. 1) needs to be varied to obtain the required optimal separator inlet ammonia mass fraction. This split fraction can be varied by changing the splitter SPL valve position, and this position in turn determines the separator inlet ammonia mass fraction. For a given value of the pump PU1 outlet pressure (which is also the separator inlet pressure), there will be only one combination of the temperature and the ammonia mass fraction at the separator inlet which results in the highest part-load performance. Thus, the separator SEP inlet temperature can be monitored in order to specify the optimal splitter valve position, and thus the optimal split fraction.

The Kalina cycle was solved in part load using Eqs. 1-11 and 27-31 in the algorithm shown in Fig. 4 where the numbers in the subscript and the component names correspond to the cycle layout in Fig. 1. In practice, it is the pumps and the splitter which will be regulated, however for modelling purposes, it is better to provide the ammonia mass fraction as the varying parameter rather than the split fraction as it speeds up the computation significantly [22]. This is because the ammonia mass fraction is always required as an input to calculate the thermophysical properties for the mixture, and therefore providing it as an input considerably reduces the number of required iterations. 


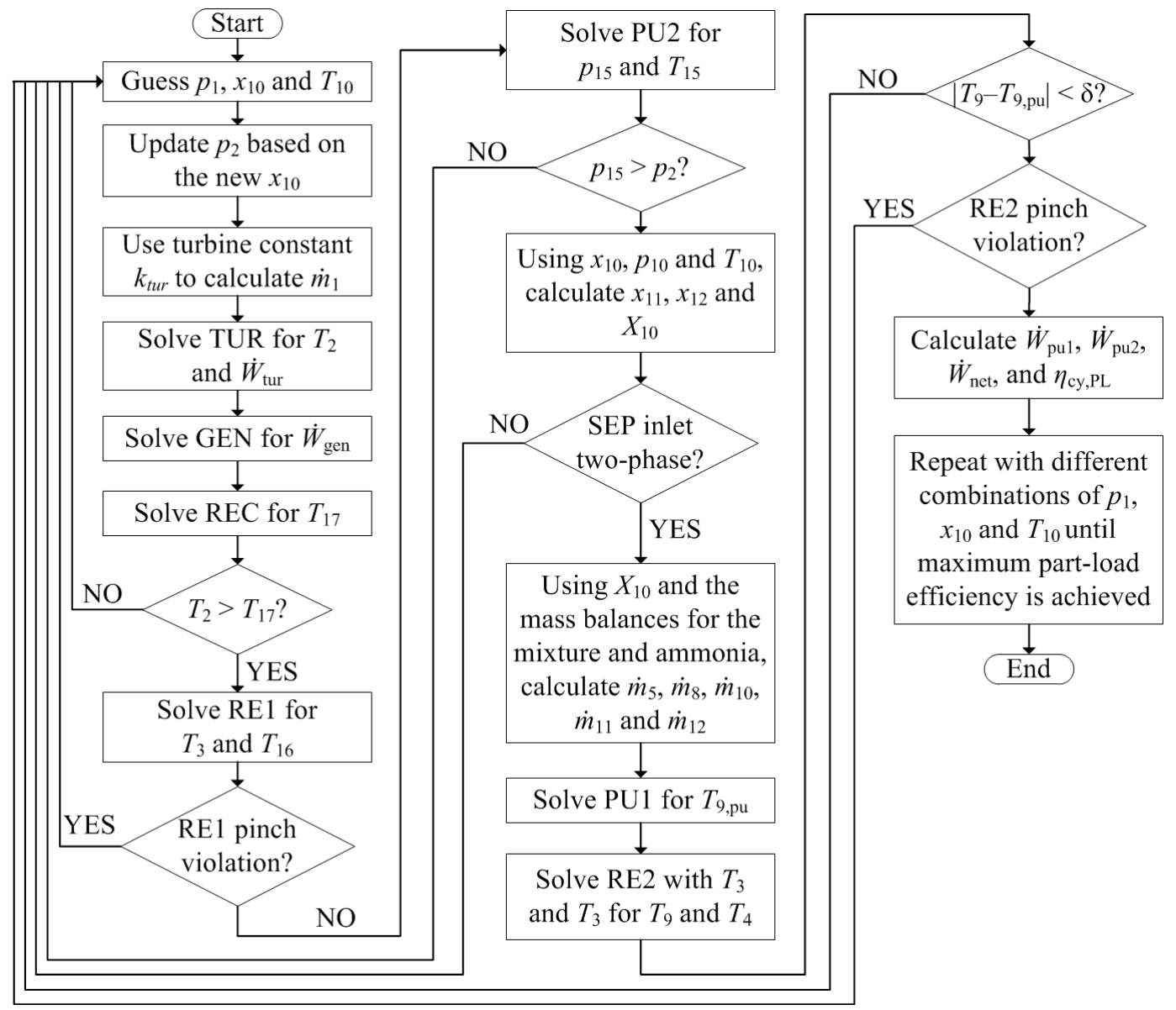

Figure 4: Part-load solution algorithm for the Kalina cycle KC12.

\section{Results}

Fig. 5 shows the optimal cycle efficiency values for the different turbine inlet ammonia mass fractions. The trend of the variation in the cycle efficiency with the turbine inlet ammonia mass fraction was explained in detail for the KC12 layout by Modi and Haglind [21]. In short, the rate of exergy destruction in the two condensers CD1 and CD2, the recuperator RE1 and the turbine TUR shows a decreasing trend; whereas the rate of exergy destruction in the recuperator RE2 first increases and then decreases. Similarly, the rate of exergy destruction in the throttle valve THV and the mixers MX1 and MX2 becomes negligible at higher values of turbine inlet ammonia mass fraction due to a better match between the temperatures of the mixing streams. The combination of these trends causes the cycle efficiency to first drop and then increase after reaching a minimum value. 


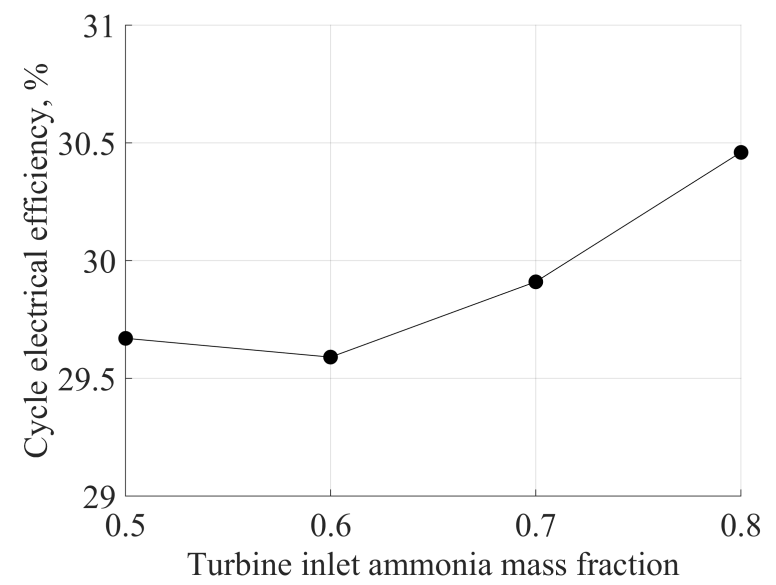

Figure 5: Optimal cycle efficiency values for different turbine inlet ammonia mass fractions.

The exemplary state points for the optimal design point for the Kalina cycle KC12 at a turbine inlet ammonia mass fraction of 0.6 are shown in Table 1 . The variation in the decision variable values for the optimal part-load performance for the same case is shown in Table 2 .

Table 1: Operation state points for the optimal design at a turbine inlet ammonia mass fraction of 0.6.

\begin{tabular}{llllll}
\hline Stream & $T\left({ }^{\circ} \mathrm{C}\right)$ & $p(\mathrm{bar})$ & $\dot{m}(\mathrm{~kg} / \mathrm{s})$ & $x$ & $h(\mathrm{~kJ} / \mathrm{kg})$ \\
\hline 1 & 500.0 & 100.00 & 26.06 & 0.6000 & 3032.7 \\
2 & 117.5 & 1.89 & 26.06 & 0.6000 & 2214.2 \\
3 & 88.0 & 1.89 & 26.06 & 0.6000 & 1856.7 \\
4 & 33.8 & 1.89 & 26.06 & 0.6000 & 679.1 \\
5 & 45.4 & 1.89 & 89.07 & 0.4037 & 340.1 \\
6 & 24.2 & 1.89 & 89.07 & 0.4037 & -21.4 \\
7 & 24.2 & 4.92 & 89.07 & 0.4037 & -20.9 \\
8 & 24.2 & 4.92 & 16.86 & 0.4037 & -20.9 \\
9 & 24.2 & 4.92 & 72.22 & 0.4037 & -20.9 \\
10 & 70.0 & 4.92 & 72.22 & 0.4037 & 404.1 \\
11 & 70.0 & 4.92 & 9.20 & 0.9597 & 1802.7 \\
12 & 70.0 & 4.92 & 63.01 & 0.3225 & 199.9 \\
13 & 49.2 & 1.89 & 63.01 & 0.3225 & 199.9 \\
14 & 49.4 & 4.92 & 26.06 & 0.6000 & 623.1 \\
15 & 24.0 & 4.92 & 26.06 & 0.6000 & 70.8 \\
16 & 25.9 & 100.00 & 26.06 & 0.6000 & 87.9 \\
17 & 96.1 & 100.00 & 26.06 & 0.6000 & 445.3 \\
\hline
\end{tabular}


Table 2: Decision variable values at the optimal part-load solutions for a turbine inlet ammonia mass fraction of 0.6 .

\begin{tabular}{llll}
\hline$L_{\mathrm{pl}}$ & $p_{1}(\mathrm{bar})$ & $T_{10}\left({ }^{\circ} \mathrm{C}\right)$ & $x_{10}$ \\
\hline 1.000 & 100 & 70.00 & 0.4037 \\
0.899 & 89.64 & 66.60 & 0.4029 \\
0.791 & 79.95 & 67.60 & 0.4021 \\
0.683 & 70.30 & 68.50 & 0.4020 \\
0.575 & 60.70 & 69.65 & 0.4028 \\
0.468 & 50.96 & 66.60 & 0.4005 \\
\hline
\end{tabular}

The part-load performance curves for different turbine inlet ammonia mass fractions are shown in Fig. 6, while the variation in the relative plant load with the relative heat input is shown in Fig. 7. In the figures, the relative plant load is the ratio of the cycle net electrical power output in part load to that at the design point, the relative cycle efficiency is the ratio of the cycle efficiency in part load to that at the design point, and the relative heat input is the ratio of the heat input to the receiver REC in part load to that at the design point.

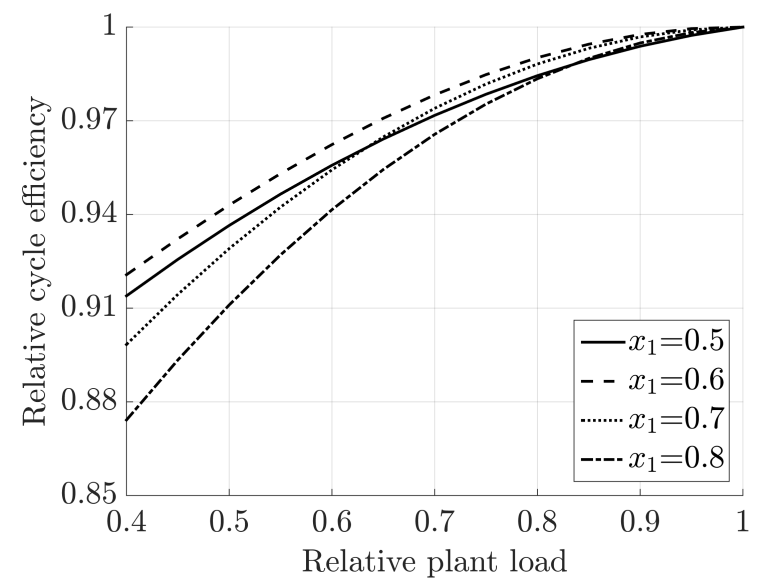

Figure 6: Part-load relative cycle efficiency for different design turbine inlet ammonia mass fractions and plant loads.

The equations representing the four part-load curves were generated using the Curve Fitting Toolbox of MATLAB. These are shown in Table 3. The equations were fitted with polynomial fitting option and a robust least-squares fitting method (Least Absolute Residuals or LAR), both standard options in the toolbox. The fitted equations for the relative heat input as a function of the plant load are shown in Table 4 . In the equations, $L_{\mathrm{pl}}$ is the relative plant load and $\dot{q}_{\mathrm{pl}}$ is the relative heat input. All the equations have a coefficient of determination $\left(R^{2}\right)$ greater than 0.997 . 


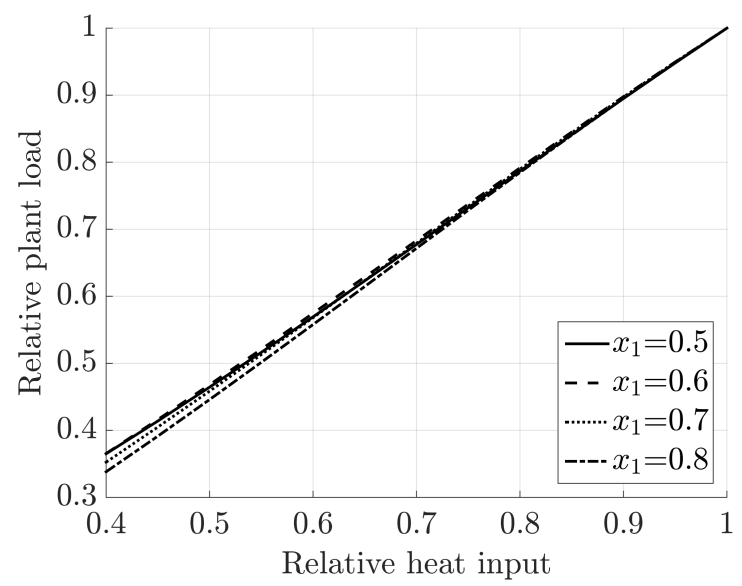

Figure 7: Part-load relative plant load for different design turbine inlet ammonia mass fractions and relative heat inputs.

Table 3: Part-load relative cycle efficiency as a function of the relative plant load.

\begin{tabular}{ll}
\hline$x_{1}$ & Part-load relative cycle efficiency \\
\hline 0.5 & $-0.1641 \cdot L_{\mathrm{pl}}^{2}+0.3732 \cdot L_{\mathrm{pl}}+0.7909$ \\
0.6 & $-0.08693 \cdot L_{\mathrm{pl}}^{3}-0.01653 \cdot L_{\mathrm{pl}}^{2}+0.291 \cdot L_{\mathrm{pl}}+0.8125$ \\
0.7 & $-0.2757 \cdot L_{\mathrm{pl}}^{2}+0.5554 \cdot L_{\mathrm{pl}}+0.7203$ \\
0.8 & $-0.3175 \cdot L_{\mathrm{pl}}^{2}+0.6542 \cdot L_{\mathrm{pl}}+0.6633$ \\
\hline
\end{tabular}

Table 4: Part-load relative plant load as a function of the relative heat input.

\begin{tabular}{ll}
\hline$x_{1}$ & Part-load relative plant load \\
\hline 0.5 & $-0.3601 \cdot \dot{q}_{\mathrm{pl}}^{3}+0.8127 \cdot \dot{q}_{\mathrm{pl}}^{2}+0.4823 \cdot \dot{q}_{\mathrm{pl}}+0.06513$ \\
0.6 & $-0.3333 \cdot \dot{q}_{\mathrm{pl}}^{3}+0.6960 \cdot \dot{q}_{\mathrm{pl}}^{2}+0.6031 \cdot \dot{q}_{\mathrm{pl}}+0.03419$ \\
0.7 & $-0.3524 \cdot \dot{q}_{\mathrm{pl}}^{3}+0.7079 \cdot \dot{q}_{\mathrm{pl}}^{2}+0.6379 \cdot \dot{q}_{\mathrm{pl}}+0.006626$ \\
0.8 & $-0.3961 \cdot \dot{q}_{\mathrm{pl}}^{3}+0.8040 \cdot \dot{q}_{\mathrm{pl}}^{2}+0.5953 \cdot \dot{q}_{\mathrm{pl}}-0.00322$ \\
\hline
\end{tabular}

\section{Discussion}

A Kalina cycle layout suitable for high temperature applications is inherently complex in nature including multiple recuperators, condensers, pumps, and an internal separator loop. Solving such a cycle in both design and part-load conditions presents a significant challenge. With regards to the part-load operation, Kalina and Leibowitz [26] presented a curve for the second law efficiency for a Kalina cycle operating as a gas turbine bottoming cycle. The paper suggests that for the part-load operation, the mass flow rate through the Kalina cycle turbine could be kept constant while varying the turbine inlet ammonia mass fraction so as to vary the enthalpy drop across the turbine. In the current study, the turbine inlet ammonia mass fraction was however maintained at its design value during part-load 


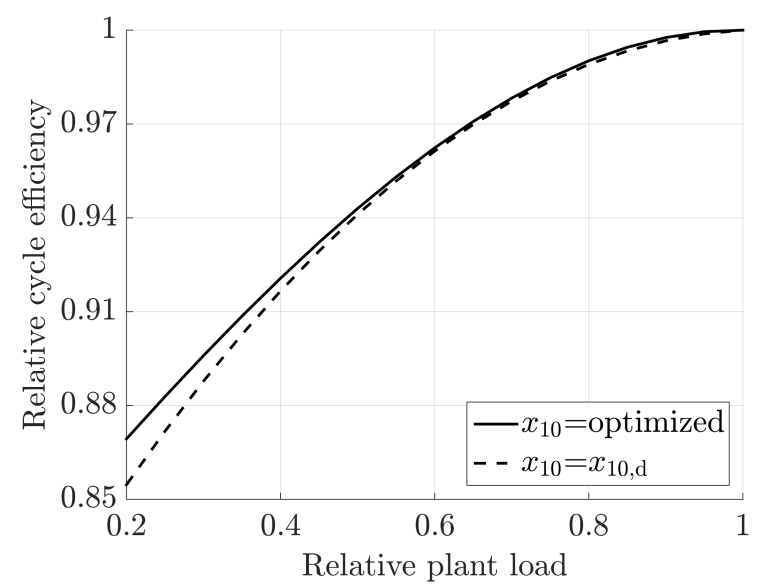

Figure 8: Part-load relative cycle efficiency for 0.6 turbine inlet ammonia mass fraction when the separator inlet ammonia mass fraction $\left(x_{10}\right)$ is maintained at its design value, or optimized in part load.

operation. This was done as it was observed from an experimental investigation [33] that the turbine power output oscillates severely when the turbine inlet ammonia mass fraction is varied simultaneously with the evaporation pressure, and the oscillations were observed for several hours. The oscillations were experienced because of the changes in the fluid specific volume with changes in ammonia mass fraction. Since the solar energy input varies throughout the day, changing the turbine inlet ammonia mass fraction frequently might not be a suitable operating strategy. Variation in the separator inlet ammonia mass fraction could however be achieved by managing the split fraction for the splitter SPL, without having to alter the turbine inlet ammonia mass fraction. This gives an opportunity to exploit the additional benefit of using fluid mixtures in the power cycle by varying the composition in order to obtain a better performance in part-load conditions. Fig. 8 highlights the relative benefit at a turbine inlet ammonia mass fraction of 0.6 as an example, between optimizing the separator inlet ammonia mass fraction in part load compared with maintaining it at its design value.

From Table 2, it may be observed that the turbine inlet pressure varies almost linearly with the change in the plant load because of the sliding pressure control strategy used for part-load operation, while maintaining the turbine inlet temperature at the design value. The separator inlet temperature and ammonia mass fraction are maintained at near-design values for a smooth transition between the different part-load conditions. The separator inlet ammonia mass fraction increases with increasing plant load, while the separator inlet temperature decreases. There is however a change in the separator inlet temperature trend at the lowest load, whereas the trend in the separator inlet ammonia mass fraction exhibits an anomaly at the second lowest load. These anomalies were experienced because it was not possible for the optimization algorithm to find a solution in that range of decision variables due to convergence failures from the thermodynamic property calculations. It may also be observed that the gap between the relative plant load value and the turbine inlet pressure widens at lower loads. This is because the separator inlet ammonia mass fraction is limited 
to $\pm 1 \%$ variation from the design value, and it restricts the turbine inlet pressure from going below a certain value to avoid pinch violation in the recuperator RE1.

Fig. 6 shows the trend of the part-load performance of the Kalina cycle with relative plant load. The curves show a decreasing performance with the decreasing plant load. It may be observed that the part-load performance at high plant loads (above $90 \%$ ) is almost the same for all the turbine inlet ammonia mass fractions because of operating close to the design point. However, the trends of the performance curves differ when going towards lower plant loads. The part-load performance of the cycle with higher values of turbine inlet ammonia mass fraction (0.7 and above) decreases more rapidly with decreasing plant load as compared with the lower values of the turbine inlet ammonia mass fraction. This is because of the significant differences in the basic solution ammonia mass fraction (stream 5 in Fig. 1), and therefore the condensing pressures. For example, the condenser CD1 pressure (also the turbine outlet pressure) at $50 \%$ relative heat input for 0.6 and 0.8 turbine inlet ammonia mass fractions is respectively 1.70 and 5.56 bar, whereas the turbine inlet pressures for the two cases are almost the same at 50.96 and 52.85 bar respectively. This results in less expansion in the turbine at low plant loads for 0.8 turbine inlet ammonia mass fraction resulting in a lower part-load efficiency for the same relative heat input. The higher the working solution ammonia mass fraction is, the higher the basic solution ammonia mass fraction will be for the Kalina cycle to operate. The higher the basic solution ammonia mass fraction is, the higher the condensing pressure will be. In fact this is the reason to have the distillation-condensation subsystem in the first place - to reduce the ammonia mass fraction in the condenser CD1 so that the working solution in the turbine can be expanded to lower pressures. Therefore, even though a higher working solution ammonia mass fraction might result in a higher design point efficiency because of more effective recuperation and condensation [22], it might also result in lower part-load performance at low plant loads because of a larger relative reduction in the turbine inlet pressure than the corresponding turbine outlet pressure relative reduction.

\section{Conclusion}

The Kalina cycle was modelled and its part-load performance was investigated. For the part-load modelling, the temperature and the ammonia mass fraction at the turbine inlet were maintained at the design values. The separator inlet ammonia mass fraction was varied in order to obtain the highest efficiency at different loads. In practice, it would be the pumps and the splitter which would be regulated in order to obtain the optimal part-load operating conditions. However, for numerical analysis, it is better to provide the ammonia mass fraction as an input to speed up the computation. The part-load performance curves and their fitted equations are presented for various plant loads and turbine inlet ammonia mass fractions. The part-load performance at higher plant loads is almost the same for the different ammonia mass fractions, whereas at lower plant loads, the part-load efficiency decreases rapidly for higher values of the turbine inlet ammonia mass fractions. 


\section{References}

[1] A.I. Kalina. Combined-cycle system with novel bottoming cycle. Journal of Engineering for Gas Turbines and Power, 106:737-742, 1984.

[2] M.R. Kærn, A. Modi, J.K. Jensen, and F. Haglind. An assessment of transport property estimation methods for ammonia-water mixtures and their influence on heat exchanger size. International Journal of Thermophysics, 2015. Available online, doi:10.1007/s10765-015-1857-8.

[3] A. Coskun, A. Bolatturk, and M. Kanoglu. Thermodynamic and economic analysis and optimization of power cycles for a medium temperature geothermal resource. Energy Conversion and Management, 78:39-49, February 2014.

[4] P. Bombarda, C.M. Invernizzi, and C. Pietra. Heat recovery from diesel engines: A thermodynamic comparison between Kalina and ORC cycles. Applied Thermal Engineering, 30(2-3):212-219, 2010.

[5] H. Junye, C. Yaping, and W. Jiafeng. Thermal performance of a modified ammonia-water power cycle for reclaiming mid/low-grade waste heat. Energy Conversion and Management, 85:453-459, 2014.

[6] C. Yue, D. Han, W. Pu, and W. He. Comparative analysis of a bottoming transcritical ORC and a Kalina cycle for engine exhaust heat recovery. Energy Conversion and Management, 89:764-774, 2015.

[7] P. Zhao, J. Wang, and Y. Dai. Thermodynamic analysis of an integrated energy system based on compressed air energy storage (CAES) system and Kalina cycle. Energy Conversion and Management, 98:161-172, 2015.

[8] V. Zare, S.M.S. Mahmoudi, and M. Yari. On the exergoeconomic assessment of employing Kalina cycle for GT-MHR waste heat utilization. Energy Conversion and Management, 90:364-374, 2015.

[9] S. Ogriseck. Integration of Kalina cycle in a combined heat and power plant, a case study. Applied Thermal Engineering, 29(14-15):2843-2848, 2009.

[10] Z. Zhang, Z. Guo, Y. Chen, J. Wu, and J. Hua. Power generation and heating performances of integrated system of ammonia-water Kalina-Rankine cycle. Energy Conversion and Management, 92:517-522, 2015.

[11] O.K. Singh and S.C. Kaushik. Energy and exergy analysis and optimization of Kalina cycle coupled with a coal fired steam power plant. Applied Thermal Engineering, 51(1-2):787-800, 2013.

[12] O.K. Singh and S.C. Kaushik. Thermoeconomic evaluation and optimization of a Brayton-RankineKalina combined triple power cycle. Energy Conversion and Management, 71:32-42, 2013.

[13] J. Wang, Z. Yan, E. Zhou, and Y. Dai. Parametric analysis and optimization of a Kalina cycle driven by solar energy. Applied Thermal Engineering, 50(1):408-415, 2013.

[14] F. Sun, W. Zhou, Y. Ikegami, K. Nakagami, and X. Su. Energy-exergy analysis and optimization of the solar-boosted Kalina cycle system 11 (KCS-11). Renewable Energy, 66:268-279, 2014.

[15] C.H. Marston. Parametric analysis of the Kalina cycle. Journal of Engineering for Gas Turbines and Power, 112:107-116, 1990.

[16] C.H. Marston and M. Hyre. Gas turbine bottoming cycles: Triple-pressure steam versus Kalina. Journal of Engineering for Gas Turbines and Power, 117(January):10-15, 1995.

[17] M.B. Ibrahim and R.M. Kovach. A Kalina cycle application for power generation. Energy, 18(9):961969, 1993.

[18] P.K. Nag and A.V.S.S.K.S. Gupta. Exergy analysis of the Kalina cycle. Applied Thermal Engineering, 18(6):427-439, 1998.

[19] E. Thorin. Power cycles with ammonia-water mixtures as working fluid. Phd thesis, KTH Royal Institute of Technology, Stockholm, 2000.

[20] C. Dejfors, E. Thorin, and G. Svedberg. Ammonia-water power cycles for direct-fired cogeneration applications. Energy Conversion and Management, 39(16-18):1675-1681, 1998.

[21] A. Modi and F. Haglind. Performance analysis of a Kalina cycle for a central receiver solar thermal power plant with direct steam generation. Applied Thermal Engineering, 65(1-2):201-208, 2014.

[22] A. Modi and F. Haglind. Thermodynamic optimisation and analysis of four Kalina cycle layouts for high temperature applications. Applied Thermal Engineering, 76:196-205, 2015.

[23] M. D. Mirolli. Kalina cycle power systems in waste heat recovery applications, 2012. 
[24] A.I. Kalina. Method of preventing nitridation or carburization of metals. United States Patent 6482272 B2, 2002 .

[25] Kalex LLC. Kalina cycle power systems for solar-thermal applications, 2015.

[26] A.I. Kalina and H.M. Leibowitz. Off-design perfomance, equipment considerations, and material selection for a Kalina system 6 bottoming cycle. In ASME COGEN-TURBO, 3rd International Symposium on Turbomachinery, Combined-Cycle Technologies and Cogeneration, volume 4, pages 347-355, Nice, France, 1989. ASME.

[27] R.W. Smith, J. Ranasinghe, D. Stats, and S. Dykas. Kalina combined cycle performance and operability. In PWR Joint Power Generation Conference, volume 30, pages 701-727. ASME, 1996.

[28] H.A. Mlcak and M.D. Mirolli. Systems and methods for increasing the efficiency of a Kalina cycle. United States Patent US8744636B2, 2014.

[29] MathWorks. MATLAB. www.mathworks.se/products/matlab, 2015.

[30] National Institute for Standards and Technology. REFPROP MATLAB Interface. www.boulder.nist.gov/div838/theory/refprop/Frequently_asked_questions.htm\#MatLabApplications, 2015.

[31] R. Tillner-Roth and D.G. Friend. A Helmholtz free energy formulation of the thermodynamic properties of the mixture \{water+ammonia\}. Journal of Physical and Chemical Reference Data, 27(1):63-96, 1998.

[32] E. Lemmon. Private communication, 2013.

[33] Y. Amano, K. Kawanishi, and T. Hashizume. Experimental investigations of oscillatory fluctuation in an ammonia-water mixture turbine system. In Proceedings of IMECE International Mechanical Engineering Congress and Exposition, volume 45, pages 391-398, Ontario, Florida, USA, 2005. ASME.

[34] F. Lippke. Simulation of the part-load behavior of a 30 MWe SEGS plant. Technical report, Sandia National Laboratories SAND95-1293, 1995.

[35] D.H. Cooke. Modeling of off-design multistage turbine pressures by Stodola's ellipse. In Energy Incorporated PEPSE User's Group Meeting, pages 205-234, Richmond, Virginia, USA, 1983. Bechtel Power Corporation.

[36] A. Ray. Dynamic modelling of power plant turbines for controller design. Applied Mathematical Modelling, 4(2):109-112, 1980.

[37] F. Haglind and B. Elmegaard. Methodologies for predicting the part-load performance of aero-derivative gas turbines. Energy, 34(10):1484-1492, 2009.

[38] P. Schwarzbözl. A TRNSYS model library for solar thermal electric components (STEC). Technical report, Deutsches Zentrum für Luft und Raumfahrt e.V. (DLR), Cologne, Germany, 2006. 